\title{
Design of a point-of-care facility for diagnosis of COVID-19 using an off-grid photovoltaic system
}

\author{
Jean Poll Alva-Araujo ${ }^{1}$ (iD) . Oscar Escalante-Maldonado ${ }^{2}$. \\ Ruddy Alfredo Cabrejos Ramos ${ }^{3}$ (D)
}

Received: 3 September 2020 / Accepted: 9 December 2020 / Published online: 4 January 2021 (c) The Author(s), under exclusive licence to Springer Nature B.V. part of Springer Nature 2021

\begin{abstract}
Severe acute respiratory syndrome coronavirus 2 (SARS-CoV-2) pandemic is one of the biggest public health issues in the last years. The WHO has reported more than 50,000 confirmed cases and more than 1,000,000 confirmed deaths around the world. Early diagnosis is essential for an appropriate patient care and infection control, so laboratory where molecular tests are held plays a main role. However, laboratory facilities for testing are limited in rural areas. Therefore, it is important to have an effective and practical point-of-care diagnostic system in order to be implemented in developing countries with limited energy access. The objective of this research is to develop an energetically autonomous point-ofcare diagnostic system for molecular detection of SARS-CoV-2. This design consists of a retractable system with an area of $15.79 \mathrm{~m}^{2}$ and 3 well-distributed interior areas to guaranty appropriate sample processing. Our point-of-care diagnostic system can be installed at a fixed place (stationary), and it can also be transported to various strategic places (itinerant). The off-grid photovoltaic system feasibility was evaluated using the PVsyst software, presenting an installed capacity of $2.79 \mathrm{KWp}$, consisting of 4 monocrystalline photovoltaic modules, a $45 \mathrm{~A}$ charge regulator and 4 batteries $(6 \mathrm{~V}, 453 \mathrm{Ah})$. The results showed a performance ratio of 0.522 , with higher losses by the full battery $(31.77 \%)$. This research determines that the proposed point-of-care diagnostic system meets all requirements to set and operate molecular techniques to diagnose infectious diseases, such as COVID-19, with good laboratory conditions, secure and eco-efficient energy, supporting the health scheme to prevent and control the spread of the virus.
\end{abstract}

Keywords Point of care $\cdot$ Retractable system $\cdot$ SARS-CoV-2 $\cdot$ Photovoltaic system $\cdot$ Energy access

Jean Poll Alva-Araujo

jepoalva@gmail.com

1 Departamento de Ingeniería Ambiental, Facultad de Ciencias, Universidad Nacional Agraria La Molina (UNALM), Av. La Molina s/n, 15024 Lima, Perú

2 Centro Nacional de Salud Pública, Instituto Nacional de Salud (INS), 15072 Lima, Perú

3 Facultad de Ciencias, Universidad Nacional de Ingeniería (UNI), Av. Túpac Amaru 210, 15333 Lima, Perú 


\section{Introduction}

The SARS-CoV-2 is a virus belonging to the coronavirus family, first reported in Wuhan city, China. This virus causes a severe acute respiratory syndrome defined as COVID-19 disease. COVID-19 has been declared by the WHO as a public health emergency of international concern (Van Kasteren et al. 2020; Sohrabi et al. 2020). Many Latin American countries have taken various strategies to mitigate the spread of COVID-19 according to the recommendations of the World Health Organization (Caicedo et al. 2020). However, the continent keeps on facing an increasing number of deaths due to its poor health systems (Giri and RSJB 2020; Sohrabi et al. 2020). Nowadays, Peru is the sixth country in the world with the highest number of SARS-CoV-2 positive cases and the second country in the world with the highest death rate of COVID-19.

One strategy to reduce the spread of coronavirus is the timely identification of positive cases (Van Kasteren et al. 2020). However, in several developing countries such as Peru, most of the laboratories that held COVID-19 tests are centralized in the capital, mainly because traditional molecular tests require sophisticated equipment for a proper operation (Seokheun 2016), causing monitoring issues (Yelin et al. 2020). To date, the number of coronavirus positive cases remains unknown as many countries have not introduced largescale population tests yet (Eberhardt et al. 2020). Thus, it is critical to find an appropriate laboratory system useful under both, good and adverse conditions.

The POCs represent a good alternative to combat COVID-19 in economically vulnerable areas (Joung et al. 2020), being used near the site of patient presentation (Haney et al. 2017). These tests provide results in a very short time, which contributes to an immediate diagnosis of infectious diseases (Ehrmeyer and Laessig 2007). To guarantee a good performance of these diagnostic systems, autonomous and stable energy is required (Seokheun 2016), especially considering that the electricity supply is limited in many slums of Peru.

Off-grid photovoltaic energy projects have become a solution in order to access to energy in developing countries (Louie and Dauenhauer 2016). This type of energy is generated by a system of photovoltaic modules, which is characterized by being non-polluting. To face the current health crisis, it is necessary to innovate in the design of structures such as POC that supports the proper application of molecular testing to diagnose COVID-19. Hence, it is important to use photovoltaic energy to complement the use of POC systems.

Previously, it has been studied the use of alternatives of photovoltaic energy to contribute considerably the improvement of health services. For example, Karaghouli and Kazmerski (2010) compared the use of a hybrid photovoltaic (PV) system with a diesel generator to electricity supply to a health clinic in Iraq. In this study, HOMER software was used to estimate the size and the cost of the PV system, their main results show that the price of electricity produced using a photovoltaic system is four times lower than the one produced by the by a diesel generator. Faced with the COVID 19 issue, Solarkiosk Solutions Company adapted its E-HUBB (Enterprise Solar Energy Integrated Infrastructure) system in a laboratory to perform PCR tests for COVID-19, HIV, malaria, tuberculosis, lung infections, hepatitis and urinary infections (SOLARKIOSK Company 2020); and SELCO foundation developed a mobile aluminum cubicle with a $24 \mathrm{~V}$ Off-grid photovoltaic system to take and process 80 to 100 samples per day of COVID-19 (SELCO Foundation 2020).

This study presents the first design of a POC powered by an off-grid photovoltaic (PV) system to carry out COVID-19 molecular diagnostic tests based on loop-mediated isothermal amplification (LAMP). The architectural design of a multifunctional POC with 2 
modules connected sequentially to optimize installation and transportation is shown. PV sizing was carried out using climatic data from the Villa El Salvador district, located in the south of Lima, Peru. The performance parameters of the PV system were calculated using the PVsyst software, which considered the energy demand of the laboratory equipment to carry out molecular diagnostic tests of COVID-19. The objective of this research is to contribute with an innovative solution to guarantee an effective and rapid detection of SARSCoV2 infections in remote places of Peru.

\section{Methodology}

This section describes the architectural design procedure and operation of POC's three interior areas. Finally, the parameters considered for the sizing of the PV system with the PVsyst software are described.

\subsection{Architectural design of POC}

The SketchUp 2019 software and AutoCAD 2019 software were used for the design of the POC for COVID-19. The design prioritizes the distribution of 3 areas with specific equipment to carry out COVID-19 molecular diagnostic tests by using the LAMP method; this design optimizes workflow in the laboratory. Currently, there is no specific regulation for the sizing of a POC. For that reason, this design uses dimensions close to the standard A 050 Health of the Building Regulations from Peru.

\subsection{Photovoltaic system design}

An off-grid PV system captures solar radiation through photovoltaic modules to produce electrical energy, which is stored into accumulators, and then extracted through a PV inverter, which is useful for converting direct current (DC) into alternating current (AC) (Fara and Craciunescu 2017; Bendib et al. 2014). These systems are characterized by having continuous and independent power supply in remote places.

Energy consumption is one of the most important parameters for the design and installation of POC systems (Petrova et al. 2019). Hence, the POC design considers an off-grid PV system to supply energy to the equipment in the laboratory area. Besides, this system guarantees energy stability, which allows avoiding damage to laboratory equipment.

Table 1 presents the power demand and the operation hours of the laboratory equipment. This table also shows that the total power is $0.787 \mathrm{~kW}$, and the requested energy is $4.074 \mathrm{kWh} /$ day, considering a maximum of 6 operation hours (i.e. 09:00 h to 15:00 h).

\subsubsection{PVsyst simulation}

The PVsyst software was used in the simulation to have accurate data on the PV system performance. This tool allows a detailed sizing of the general performance, energy production, and the main losses related to the components and climatic parameters in off-grid and on-grid PV systems (Manoj et al. 2017; Sidney et al. 2020). The load energy specified in the PVsyst software is the direct current energy before the inverter, for this reason, this parameter was not considered in the evaluation. 
Table 1 Load Chart

\begin{tabular}{lllll}
\hline Equipment & Quantity & Power $(\mathrm{W})$ & Use time $(\mathrm{h} /$ day $)$ & Energy $(\mathrm{kWh} /$ day $)$ \\
\hline Led lamps & 4 & 8 & 2 & 0.064 \\
Thermoblock & 1 & 100 & 6 & 0.60 \\
Biosafety cabinet & 1 & 210 & 4 & 0.84 \\
Refrigerator & 2 & - & - & 1.60 \\
PCR cabinet & 1 & 185 & 2 & 0.37 \\
Laptop & 1 & 80 & 6 & 0.48 \\
Others & 1 & 20 & 6 & 0.12 \\
\hline
\end{tabular}

The chosen study area was the Villa El Salvador district $\left(12.21^{\circ} \mathrm{S}, 76.97^{\circ} \mathrm{W}\right)$, located in the south of Lima, Peru. Meteonorm software (V7.2 2017) was used to import climatic data of solar irradiation and available energy from this geographical zone.

\subsubsection{Performance indices of the off-grid PV system}

The performance parameters considered in the PVsyst software are used in this study to evaluate the performance of the POC photovoltaic system.

2.2.2.1 Performance ratio The performance ratio (PR) is a parameter that indicates the overall efficiency of the system concerning the installed nominal power and the incident energy (Sharma et al. 2020; Belmahdi and El Bouardi 2020). This parameter is calculated as shown in Eq. 1, where Yf is the system performance and $\mathrm{Yr}$ is the reference performance.

$$
P R=Y f / Y r
$$

2.2.2.2 Solar fraction The solar fraction (SF) is the parameter that indicates whether the PV modules can supply the energy required by the load (Yahyaoui et al. 2015). This parameter is calculated as shown in Eq. 2, where E User is the energy supplied to the user and E Load is the user's energy requirement.

$$
S F=\text { EUser } / \text { ELoad }
$$

\subsubsection{PV system orientation and tilt}

The POC is considered an itinerant system; however, the laboratory operation is a stationary system. For that reason, it is important to define the orientation and tilt of the PV modules to optimize the system.

Using the PVsyst software, we consider annual solar radiation data to produce a fixed roof with an optimal tilt angle of $15^{\circ}$. This angle was fixed as a function of the maximum solar radiation that could be captured through the PV module (Sidney et al. 2020). Moreover, our PV modules must have a north orientation with azimuth $0^{\circ}$, since the study area is located in the southern hemisphere (Fig. 1). 
Tilt $15^{\circ}$
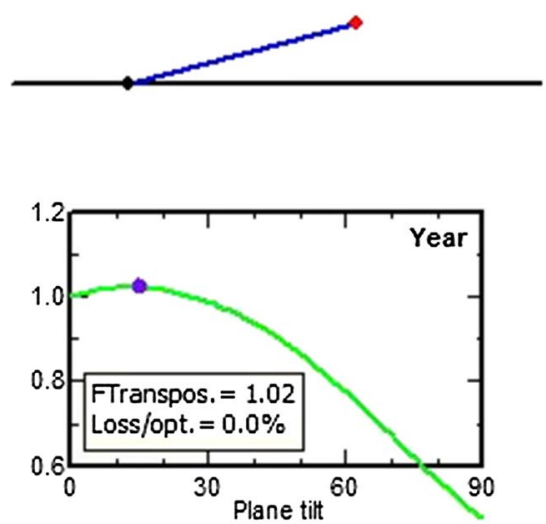

Azimuth $0^{\circ}$
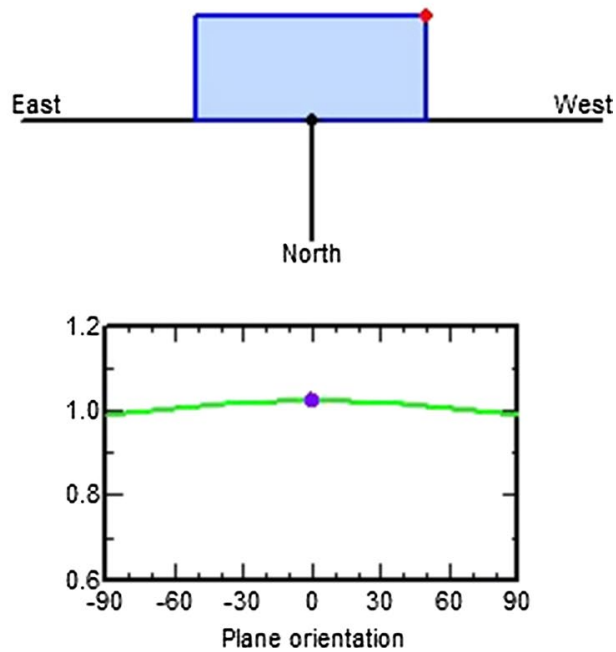

Fig. 1 Optimal tilt and orientation values for annual irradiation

\subsubsection{Technical specifications of the PV system}

The proposed PV system is $24 \mathrm{~V}$ and is made up of a PV array of 4 monocrystalline PV modules (each $380 \mathrm{Wp}$ ), i.e. two modules in series and two such PV module strings in parallel. The PV system is complemented by a charge controller (45 A), 4 lead-acid batteries $(6 \mathrm{~V}, 453 \mathrm{Ah})$, and a PV inverter. Table 2 shows the technical specifications of the components of the off-grid PV system for the POC.

Table 2 PV system description

\begin{tabular}{ll}
\hline PV module characteristics & Canadian solar \\
\hline Power & $380 \mathrm{Wp}$ \\
Conversion Efficiency & $19.15 \%$ \\
Short circuit current (ISC) & $10.01 \mathrm{~A}$ \\
Open circuit voltage (VOC) & $47.8 \mathrm{~V}$ \\
Maximum current (Imp) & $9.50 \mathrm{~A}$ \\
Maximum voltage (Vmp) & $40.0 \mathrm{~V}$ \\
Charge controller Characteristics & Victron Energy \\
System voltage & $24 \mathrm{~V}$ \\
Load current & $45 \mathrm{~A}$ \\
Battery characteristics & Rolls Battery \\
Nominal voltage & $6 \mathrm{~V}$ \\
Rater capacity & $453 \mathrm{Ah}, \mathrm{C} 10$ \\
Inverter characteristics & Victron Energy \\
Output power & $2000 \mathrm{~W}$ \\
System voltage & $24 \mathrm{~V}$ \\
Max efficiency & $94 \%$ \\
\hline
\end{tabular}




\section{Results and discussion}

\subsection{POC for COVID-19 testing design}

The POC design is made of 2 modules (module 1 and module 2) with increasing dimensions, which allows module 2 to be folded into module 1 during disassembly (retractable design). The connection of these modules will speed up the time to perform a COVID19 test (Petrova et al 2019). In the module 1, there is an amplification area, while in the module 2 , there is a pre-analytical area and a pre-amplification area, each of them has a specific function in the POC.

In the pre-analytical area, samples are received, aliquoted and encoded; at the same time, genetic material is extracted in a biosafety cabinet. Also, there is a small area for the storage of the PV system components (Fig. 4). In the pre-amplification area, the preparation of the reaction mixture is carried out in a PCR cabinet. For that reason, this area is separated from the others. Finally, in the area of amplification, the amplification of the genetic material is carried out in the isothermal thermoblock (LAMP methodology).

The amplification area, the pre-analytical area, and the pre-amplification area have dimensions of $2.6 \times 2.2 \mathrm{~m}, 2.48 \times 2.42 \mathrm{~m}$, and $2.48 \times 1.64 \mathrm{~m}$, respectively (Fig. 2). These measures have been used to facilitate the folding and transport of the POC. In the module 1, the highest and lowest heights are 2.95 and $2.3 \mathrm{~m}$, respectively, while in the module 2, those are 2.76 and $2.13 \mathrm{~m}$. These measures allow the generation of a $15^{\circ}$ slope in the POC roof, what guarantees the optimal operation of the PV system, according to the sizing of the PVsyst software.

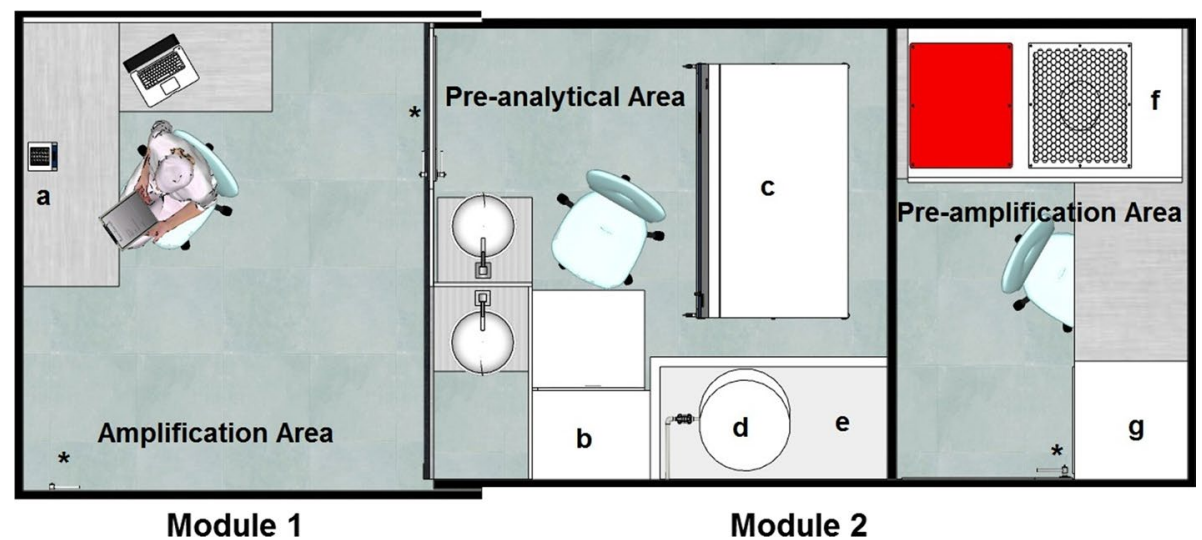

Fig. 2 Projection of the POC interior areas a Thermoblock, b Refrigerator 1, c Biosafety cabinet, $\mathbf{d}$ Water tank, e PV system, f PCR cabinet and $\mathbf{g}$ Refrigerator 2, *Doors 
The POC design has three $0.9 \times 1 \mathrm{~m}$ swing doors $(2$ external and 1 internal), the external doors are in the amplification area and the pre-amplification area, and the internal door connects the pre-analytical area with the amplification area. The configuration of these doors allows optimizing the workflow of medical staff during the performance of molecular testing for COVID-19. On the other hand, the amplification area has a sliding window of $1 \times 1.10 \mathrm{~m}$, which allows natural ventilation and lighting in this area (OMS 2005). However, the entrance of air with particles near the equipment should be avoided (Petrova et al. 2019). For that reason, the pre-analytical area and the pre-amplification area do not consider windows, since within these areas there are the biosafety and the PCR cabinets.

For the construction of this POC, a metallic structure made of electro-welded steel square tubes should be considered, while for the covering of the walls and the roof, aluminum sheets should be used. The walls should have an interior and exterior metallic coating painted with polyester resin glued, which will allow maintaining the asepsis in the interior environments of the POC. Besides that, the roof should have an exterior coating of waterproofing membrane with UV treatment. Finally, the floor must be made up of solid hydro-resistant sheets and it must be covered with high traffic vinyl flooring, antibacterial, non-slip and resistant to chemicals (Fig. 3).

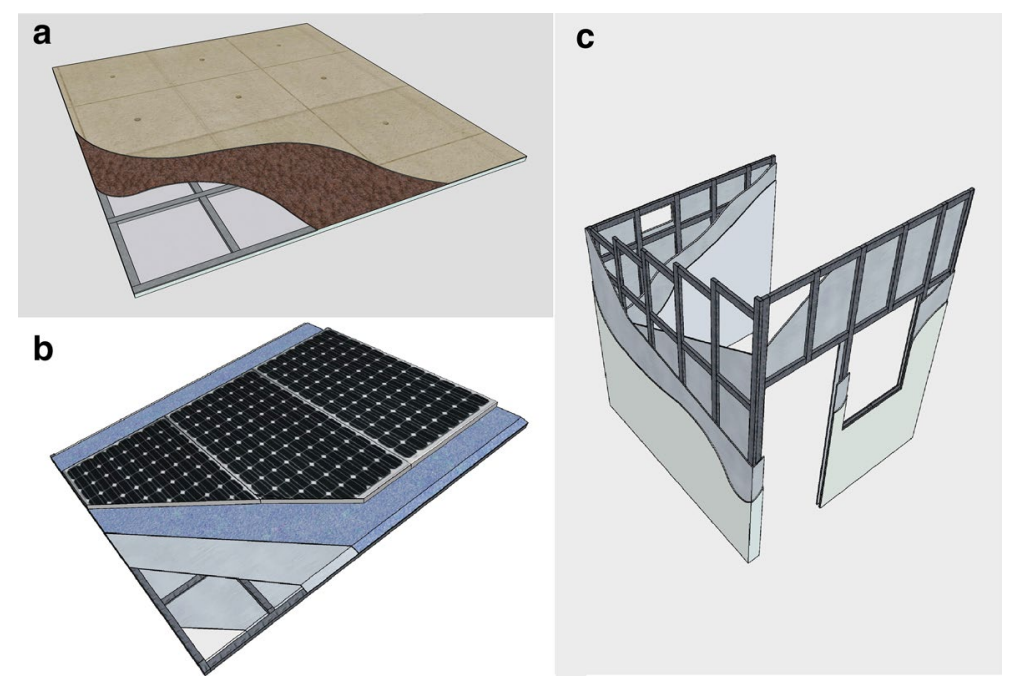

Fig. 3 Proposed materials: a Solid hydro-resistant sheets, b Exterior coating of waterproofing membrane, and $\mathbf{c}$ metallic structure and aluminum sheets

The installation of the PV modules on the roof should be carried out through aluminum rails, which will be fixed to the roof through stainless screws $(18 \mathrm{~cm})$. These modules should be mounted on the metal rails and fastened to them through aluminum fixing hooks. In each POC module, 2 monocrystalline PV modules of $2 \times 0.992$ m must be placed with a $15^{\circ}$ slope. Due to our location (southern hemisphere), the PV modules must be located facing north. Finally, the other components of the PV system must be located in the $1.2 \times 0.6 \mathrm{~m}$ compartment located in the pre-analytical area (Fig. 4). 
Module 1

Module 2

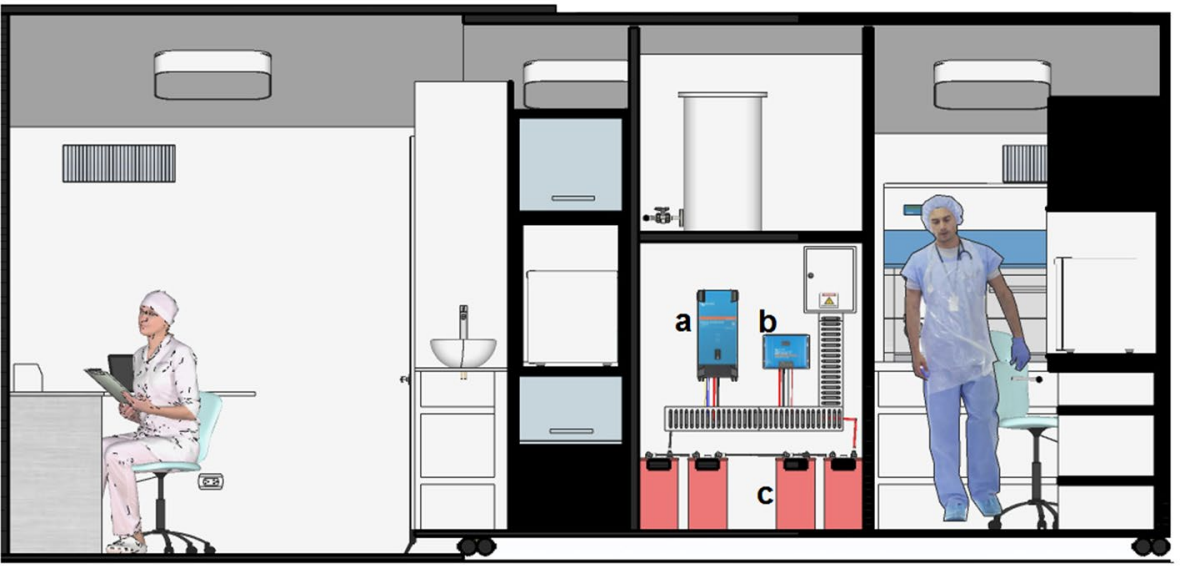

Amplification Area

Pre-analytical Area Pre-amplification Area

Fig. 4 Projection of the PV system components: a Inverter, b Charge controller, and $\mathbf{c}$ Batteries
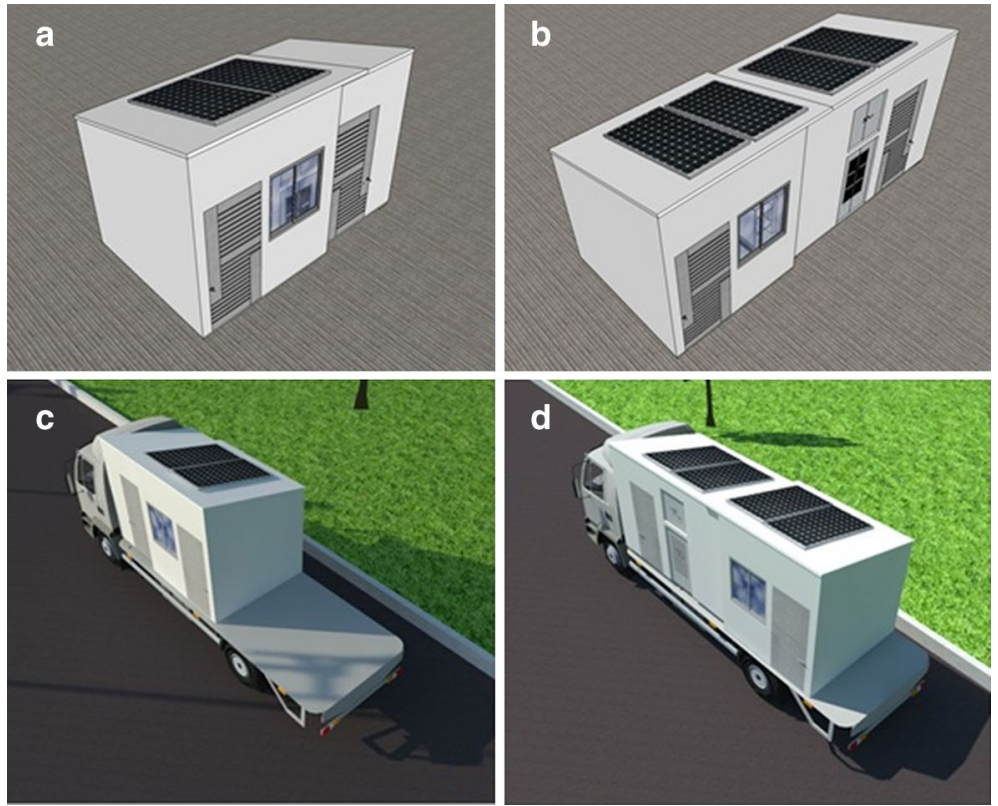

Fig. 5 Stationary system: a POC folded, b POC unfolded and Itinerant system: c POC folded, d POC unfold

The POC design for COVID-19 is a multifunctional system since it can be installed at a fixed point (stationary system). However, the POC can also be transferred to various strategic points of the national territory for short periods (itinerant system), which facilitates the detection of COVID-19 in remote places (Fig. 5). Additionally, the retractable 


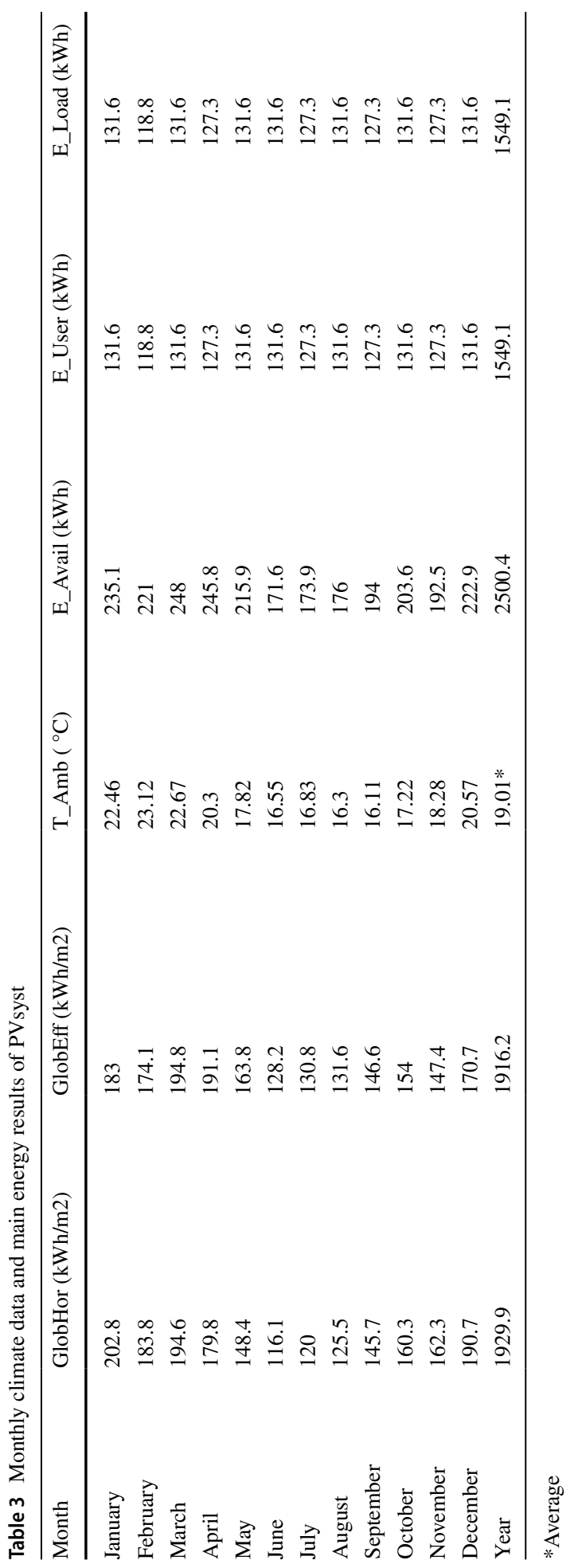


design of the POC reduces its total area $\left(15.79 \mathrm{~m}^{2}\right)$ by $37 \%$ when it is folded, this feature allows optimizing the space inside the vehicles during their transport.

\subsection{Annual energy balance}

PV modules are very productive in the Latin American region due to high solar irradiation (Petrova et al. 2019). Nevertheless, the performance of these modules depends on climatic parameters such as ambient temperature, which is closely related to incident solar insolation (Ramanan et al. 2019). Indeed, Table 3 presents the lowest temperature values for June, July, and August, corresponding to the lowest values of available solar radiation. This climatic characteristic is typical for Lima, which also has some cloudy days during the winter season. However, in the PV sizing, we consider this city because it has more than $50 \%$ of COVID-19 positive cases in Peru.

\subsection{Performance analysis of PV system}

Figure 6 shows the parameters related to the global incident radiation in the collector plane and normalized by the installed power ( $\mathrm{kWh} / \mathrm{kWp} / \mathrm{day})$, which are the unused energy (Lu) due to the full battery, collection loss (Lc) due to PV array, system loss and batteries charging (Ls), and system performance (Yf) due to daily useful system power. These parameters are considered in the International Standard IEC 61,724 to evaluate the performance of PV systems.

The unused energy due to the full battery $(\mathrm{Lu})$ presents lower losses in June, July, and August, which is related to the lower energy stored in the batteries by the lower solar radiation during these months. On the other hand, the collection loss (Lc) and the system loss (Ls) did not present many variable values during the year; it was also established that the energy supplied to the user (Yf) is $2.79 \mathrm{kWh} / \mathrm{kWp} /$ day.

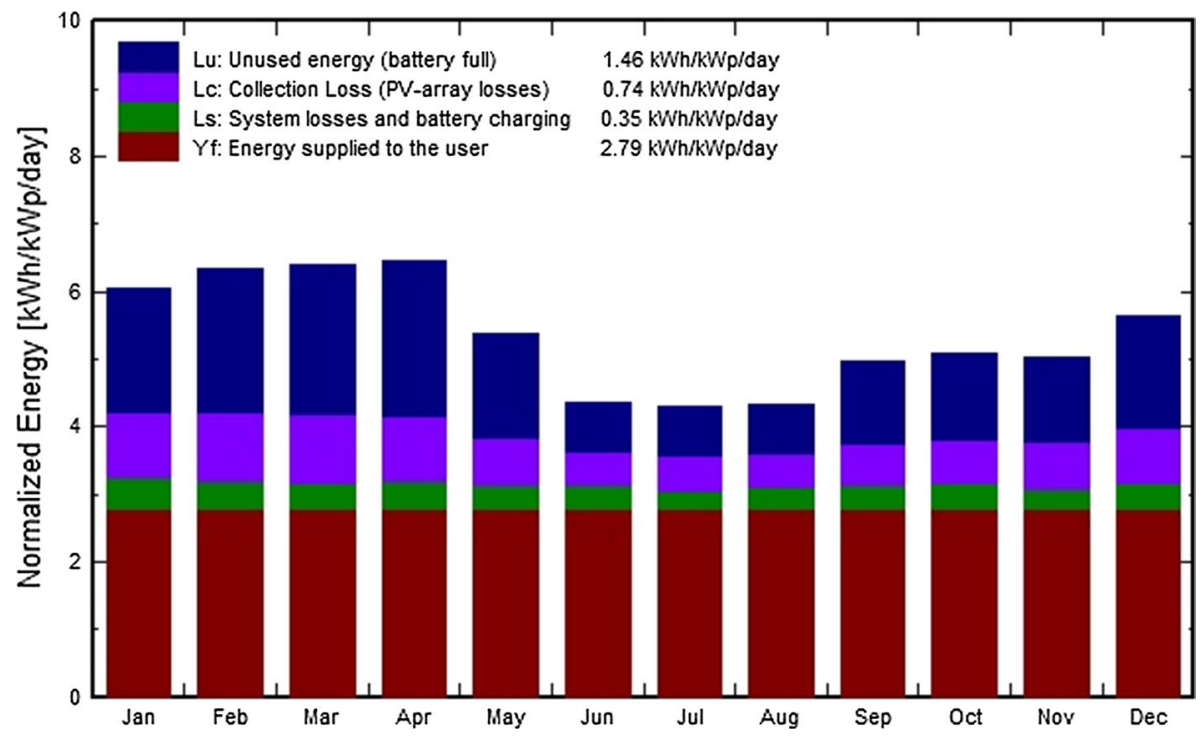

Fig. 6 Normalized Production (per installed kWp) 
The performance ratio (PR) indicates the proportion of energy supply that is available after discounting energy losses (wiring losses, module quality losses, thermal losses, mismatch losses, strings losses, shading losses, regulation losses, IAM losses, etc.). Figure 7 shows that the performance ratio for our system is 0.522 , considering that the highest energy losses happened due to a full battery (31.77\%).

In the PV sizing, the yield is estimated through the solar fraction (SF) (Sidney et al. 2020). For this reason, the PVsyst performance analysis considers the calculation of this parameter. Figure 7 shows that SF is 1, which indicates that our PV system manages to satisfy the energy demand of the POC equipment laboratory over a year.

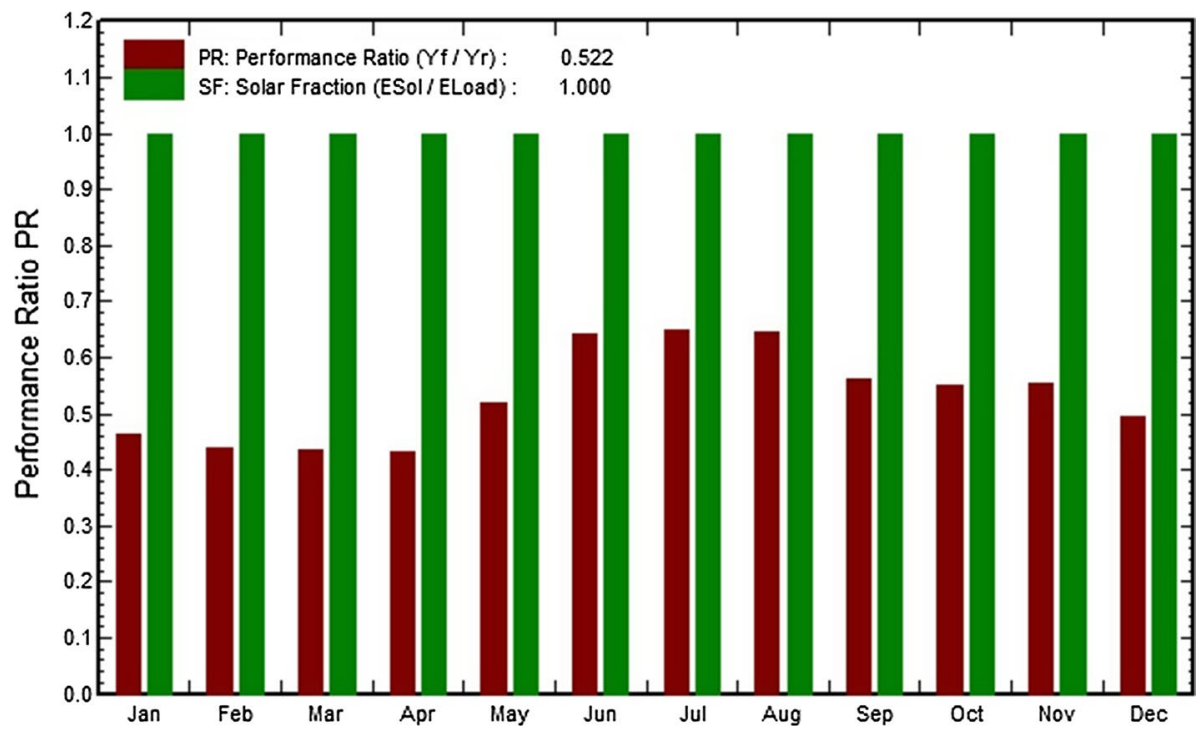

Fig. 7 Performance Ratio and Solar Fraction

\subsection{Analysis of energy losses in the off-grid PV system}

The loss diagram details the quality of the PV design that has been simulated and identifies the sources of loss. Figure 8 shows that the horizontal global irradiation is 1930 $\mathrm{kWh} / \mathrm{m}^{2}$ and the effective irradiation in the collecting plane is $1916 \mathrm{kWh} / \mathrm{m}^{2}$. Furthermore, the chosen PV modules have an efficiency of $19.15 \%$, so that after the PV conversion, the nominal energy in standard test conditions (STC) is $2913 \mathrm{kWh}$.

Figure 8 shows that the main energy loss is the unused energy due to the full battery (31.77\%), which coincides with (Irwan et al. 2015). This happens because in this study high power PV modules and only 4 batteries $(6 \mathrm{~V}, 453 \mathrm{Ah})$ are considered. The energy loss per full battery could have been less if we had considered batteries of greater capacity or a greater number of batteries in our sizing. However, increasing the number of batteries is a higher investment in comparison with PV modules (Benavente et al. 2019). Figure 8 also shows that the energy loss due to temperature is $7.52 \%$. 


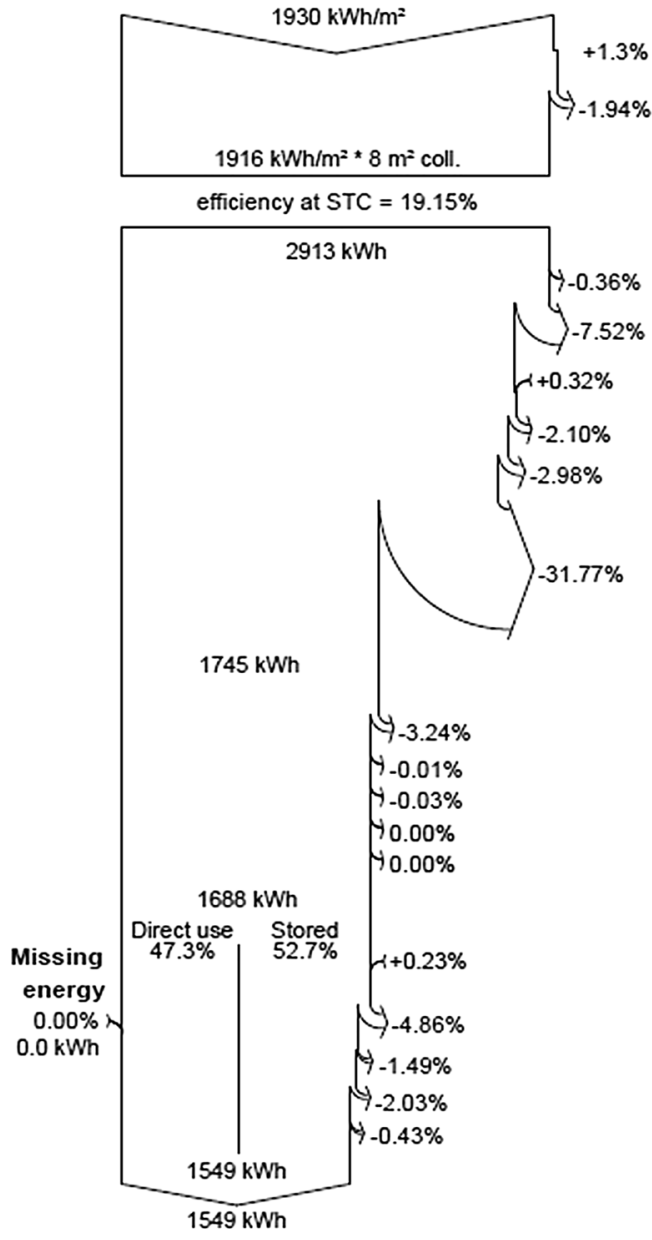

Global horizontal irradiation

Global incident in coll. plane

IAM factor on global

Effective irradiation on collectors

PV conversion

Array nominal energy (at STC effic.)

$\mathrm{PV}$ loss due to irradiance level

PV loss due to temperature

Module quality loss

Mismatch loss, modules and strings

Ohmic wiring loss

Unused energy (battery full)

Effective energy at the output of the array

Converter Loss during operation (efficiency)

Converter Loss over nominal conv. power

Converter Loss due to power threshold

Converter Loss over nominal conv. voltage

Converter Loss due to voltage threshold

Converter losses (effic, overload)

Battery Storage

Battery Stored Energy balance

Battery efficiency loss

Charge/Disch. Current Efficiency Loss

Gassing Current (electrolyte dissociation)

Battery Self-discharge Current

Energy supplied to the user

Energy need of the user (Load)

Fig. 8 Loss Diagram

This is related to the increase in cell temperature due to high ambient temperatures (Ramanan et al. 2019). In the particular case of Lima, the highest temperatures occur during the summer months (southern hemisphere). Nonetheless, this does not mean that the designed POC can be adapted to other climatic conditions. Mountain climates in Peru have favorable conditions of temperature and solar radiation for PV modules (Fig. 9). 
Fig. 9 POC for COVID-19 testing

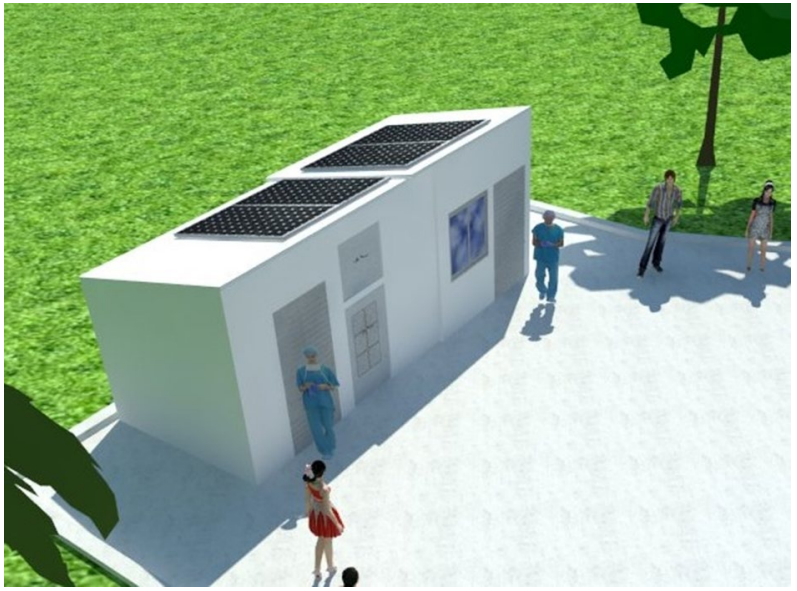

\subsection{Advantages of the POC to mitigate the COVID-19 pandemic}

The timely laboratory diagnosis is very important for the proper management and control of diseases; especially COVID-19, considering its high infective level. Having a molecular diagnostic platform at the POC could be an essential Public Health strategy.

To date, COVID-19 sampling systems have been developed that use PV modules to supply energy for sample storage and transport. Nevertheless, these systems are not able to process these samples at the point of care. Although the construction of specialized laboratories for COVID19 testing supplied completely with PV energy is presented as a good alternative, its main disadvantage lies in the logistics to be transported to different geographical areas. Given that the specialized literature does not report any work with a POC to COVID-19 testing with LAMP, this proposed design would be the first in Peru, and even, given that this system works with a PV On-grid system, it can be assumed that it would be the first worldwide with these characteristics.

The implementation of the POC for COVID-19 in the Lima slums will allow us to carry out 200 molecular tests per day using LAMP methodology (considering 6 work hours). This methodology has been reported as a cost-effective method, easy to operate, and applicable at the POC (Song et al. 2016). Additionally, this method has been shown to have high sensitivity and specificity, superior to other molecular methods such as PCR (Escalante et al. 2019).

Many research groups worldwide, including the National Institute of Health of Peru (INS), have developed LAMP for the detection of various etiologies, demonstrating its effectiveness. Considering the current COVID-19 pandemic scenario and the limited conditions for diagnosis of the disease in public laboratories, LAMP turns out to be the most suitable alternative for the molecular detection of SARS CoV-2 (COVID-19).

Currently, many countries are working hard to stop the spread of SARS-CoV 2 (Giri and RSJB 2020). The INS in Peru, fulfilling its most important functions, research and technological development, has explored the option of developing a COVID-19 diagnostic kit based on LAMP, to the production and distribution at a national level, and thereby contributing to the decentralization of laboratory diagnosis. The construction and implementation of a POC would be an innovative and sustainable option to complement the diagnostic tests for coronavirus using the LAMP method.

Furthermore, this system is also designed for the molecular diagnosis of important infectious diseases in Peruvian Public Health such as Tuberculosis, Dengue, Leptospira, and Malaria. 


\section{Conclusion}

Infection diseases, including COVID-19, are a worldwide public health problem and early detection of the infection with laboratory tests is essential. In that context, our POC is a good alternative to bring diagnostics to everybody.

The POC for COVID-19 molecular testing is a multi-functional platform and comprises a robust infrastructure, a consistent power system and adequate laboratory equipment guaranteeing its sustainability. The retractable design allows for quick assembly and disassembly, which is logistically efficient during transportation and installation. Also, the POC has three interior areas, which allow to optimize the workspace for technicians.

The PV system design adjusts well to the climatic conditions of Lima, presenting low energy losses due to temperature. However, our system could be used more efficiently in the climatic conditions of Peruvian Andean zones. Moreover, the highest energy losses were due to a full battery (31.77\%), because our system considered high-power PV modules $(380 \mathrm{Wp})$ and a limited number of batteries. As a final result, a solar fraction of 1 was obtained, which indicates that the dimensioned PV system allows satisfying the energy demand of the equipment in the POC laboratory area throughout one year.

The combination of a POC with a photovoltaic system provides a solution to approach diagnosis of COVID-19 to different areas of resource-limited countries such as Peru, including regions with limited access to electricity supply.

Acknowledgements The authors would like to thank Arch. Paola Huaitalla Núñez for assisting in the architectural design of the POC and Dr. Fany Cardenas Bustamante from the National Institute of Health (INS), for her support in the development of the proposal presented in this article. The authors also want to express their deep sense of gratitude to MSc. Rafal Fejfer of Oxford University for his great support in the final revision of the present article.

Author contributions Not applicable.

Funding Not applicable.

\section{Compliance with ethical standards}

Conflict of interest Not applicable.

Avaliablity of data and material Not applicable.

Code availablity Not applicable.

\section{References}

Al-Karaghouli, A., \& Kazmerski, L. L. (2010). Optimization and life-cycle cost of health clinic PV system for a rural area in southern Iraq using HOMER software. Solar Energy, 84(4), 710-714. https:// doi.org/10.1016/j.solener.2010.01.024.

Belmahdi, B., \& El Bouardi, A. (2020). Solar Potential Assessment using PVsyst Software in the Northern Zone of Morocco. Procedia Manufacturing, 46, 738-745. https://doi.org/10.1016/j.promf g.2020.03.104.

Benavente, F., Lundblad, A., Campana, P. E., Zhang, Y., Cabrera, S., \& Lindbergh, G. (2019). Photovoltaic/battery system sizing for rural electrification in Bolivia: Considering the suppressed demand effect. Applied Energy, 235, 519-528. https://doi.org/10.1016/j.apenergy.2018.10.084. 
Bendib, B., Krim, F., Belmili, H., Almi, M. F., \& Boulouma, S. (2014). Advanced Fuzzy MPPT Controller for a stand-alone PV system. Energy Procedia, 50, 383-392. https://doi.org/10.1016/j.egypr o.2014.06.046.

Caicedo, Y., Rebellón, D. E., Peñaloza, M., Cortés, H. F., \& Méndez, Y. R. (2020). Effective Reproductive Number estimation for initial stage of COVID-19 pandemic in Latin American Countries. International Journal of Infectious Diseases, 95, 316-318. https://doi.org/10.1016/j.ijid.2020.04.069.

Eberhardt, J. N., Breuckmann, N. P., \& Eberhardt, C. S. (2020). Multi-Stage Group Testing Improves Efficiency of Large-Scale COVID-19 Screening. Journal of Clinical Virology. https://doi. org/10.1016/j.jcv.2020.104382.

Ehrmeyer, S. S., \& Laessig, R. H. (2007). Point-of-care Testing, Medical Error, and Patient Safety: A 2007 Assessment. Clinical Chemistry and Laboratory Medicine, 45(6), 766-773. https://doi. org/10.1515/cclm.2007.164.

Escalante, O., Gustavo, R., Paquita, M., Marcelo, A., Pacheco, E., Cabezas, C., et al. (2019) Development and validation of loop-mediated isothermal amplification for the detection of the Zika virus. Rev Per Med Exp y Salud Pública, 36 (3): 442-447 https://doi.org/10.17843/rpmesp.2019.363.3941

Fara, L., \& Craciunescu, D. (2017). Output analysis of stand-alone PV systems: modeling, simulation and control. Energy Procedia, 112, 595-605. https://doi.org/10.1016/j.egypro.2017.03.1125.

Giri, A. K., \& RSJB, D. (2020). Charting the challenges behind the testing of COVID-19 in developing countries: Nepal as a case study. Biosafety and Health, 2(2), 53-56. https://doi.org/10.1016/j.bshea 1.2020.05.002.

Haney, K., Tandon, P., Divi, R., Ossandon, M. R., Baker, H., \& Pearlman, P. C. (2017). The Role of Affordable, Point-of-Care Technologies for Cancer Care in Low- and Middle-Income Countries: A Review and Commentary. IEEE Journal of Translational Engineering in Health and Medicine, 5, 1-14. https:// doi.org/10.1109/JTEHM.2017.2761764.

Irwan, M., Amelia, A. R., Irwanto, M., Fareq, M. A., Zhe Leow, W., Gomesh, N., et al. (2015). Stand-alone photovoltaic (SAPV) system assessment using PVSYST software. Energy Procedia, 79, 596-603. https ://doi.org/10.1016/j.egypro.2015.11.539.

Joung, J., Ladha, A., Saito, M., Segel, M., Bruneau, R., Huang, M. W., et al. (2020). Point-of-care testing for COVID-19 using SHERLOCK diagnostics. medRxiv. https://doi.org/10.1101/2020.05.04.20091231

Louie, H., \& Dauenhauer, P. (2016). Effects of load estimation error on small-scale off-grid photovoltaic system design, cost and reliability. Energy for Sustainable Development, 34, 30-43. https://doi. org/10.1016/j.esd.2016.08.002.

Manoj, N., Rohit, M., Rejoice, P. R., \& Mathew, M. (2017). Performance analysis of 100 kWp grid connected Si-poly photovoltaic system using PVsyst simulation tool. Energy Procedia, 117, 180-189. https://doi.org/10.1016/j.egypro.2017.05.121.

OMS (2005). Manual de Bioseguridad en Laboratorio, Ginebra 2005. Tercera edición pg.13. https://www. who.int/topics/medical_waste/manual_bioseguridad_laboratorio.pdf?ua=1. Accessed 11 August 2020.

Petrova, E. V., Avadhanula, V., Michel, S., Gincoo, K. E., Piedra, P. A., \& Anandasabapathy, S. (2019). Remote Laboratory Management: Respiratory Virus Diagnostics. Journal of Visualized Experiments, 146, 1-13. https://doi.org/10.3791/59188.

Ramanan, P., Murugavel, K., \& Karthick, A. (2019). Performance analysis and energy metrics of gridconnected photovoltaic systems. Energy for Sustainable Development, 52, 104-115. https://doi. org/10.1016/j.esd.2019.08.001.

Seokheun, C. (2016). Powering point-of-care diagnostic devices. Biotechnology advances, 34, 321-330. https://doi.org/10.1016/j.biotechadv.2015.11.004.

Sharma, R., Sharma, S., \& Tiwari, S. (2020). Design optimization of solar PV water pumping system. Materials Today: Proceedings, 21(3), 1673-1679. https://doi.org/10.1016/j.matpr.2019.11.322.

Sidney, S., Thomas, J., \& Lal Dhasan, M. (2020). A standalone PV operated DC milk chiller for Indian climate zones. Sādhanā, 45(110), 1-10. https://doi.org/10.1007/s12046-020-01334-0.

Sohrabi, C., Alsafi, Z., O’Neill, N., Khan, M., Kerwan, A., Al, A., et al. (2020). World Health Organization declares global emergency: A review of the 2019 novel coronavirus (COVID-19). International Journal of Surgery, 76, 71-76. https://doi.org/10.1016/j.ijsu.2020.02.034.

Song, J., Mauk, M. G., Hackett, B. A., Cherry, S., Bau, H. H., \& Liu, C. (2016). Instrument-Free Pointof-Care Molecular Detection of Zika Virus. Analytical Chemistry, 88(14), 7289-7294. https://doi. org/10.1021/acs.analchem.6b01632.

SOLARKIOSK Company. (2020). Solar Powered Molecular Virology Testing Lab. https://www.solarkiosk .eu/solar-powered-molecular-virology-testing-lab-for-covid-19-hiv-malaria-tuberculosis-etc/. Accessed 1 November 2020

SELCO Foundation. (2020). Sustainable Energy Access for COVID-19 Testing. https://www.seforall.org/ system/files/2020-05/COVID-19-testing-solar.pdf. Accessed 1 November 2020 
Van Kasteren, P. B., van der Veer, B., Van den Brink, S., Wijsman, L., Jonge, J., Van den Brandt, A., et al. (2020). Comparison of seven commercial RT-PCR diagnostic kits for COVID-19. Journal of Clinical Virology, 128, 104412. https://doi.org/10.1016/j.jcv.2020.104412.

Wang, Z., Xie, W., Lu, Y., Li, H., Wang, Z., \& Li, Z. (2019). Dynamic and static testing methods for shear modulus of oriented strand board. Construction and Building Materials, 216, 542-551. https://doi. org/10.1016/j.conbuildmat.2019.05.004.

WHO. (2020). Laboratory biosafety guidance related to the novel coronavirus (2019-nCoV). https://www. who.int/docs/default-source/coronaviruse/laboratory-biosafety-novel-coronavirus-version-1-1.pdf. Accessed 28June 2020.

WHO. (2020). Laboratory testing for 2019 novel coronavirus disease (2019-nCoV) in suspected human cases. https:/www.who.int/publications/i/item/laboratory-testing-for-2019-novel-coronavirus-in-suspe cted-human-cases-20200117. Accessed 10 July 2020.

Yahyaoui, I., Tina, G., Chaabene, M., \& Tadeo, F. (2015). Design and evaluation of a renewable water pumping system. IFAC-PapersOnLine, 48(30), 462-467. https://doi.org/10.1016/j.ifacol.2015.12.422.

Yelin, I., Aharony, N., Shaer, A., Argoetti, A., Messer, E., Berenbaum, D., et al. (2020). Evaluation of COVID-19 RT-qPCR test in multi-sample pools. Clinical Infectious Diseases. https://doi.org/10.1093/ cid/ciaa531.

Publisher's Note Springer Nature remains neutral with regard to jurisdictional claims in published maps and institutional affiliations. 